\title{
Sympathetic Schwannoma
}

National Cancer Institute

\section{Source}

National Cancer Institute. Sympathetic Schwannoma. NCI Thesaurus. Code C5421.

A benign tumor derived from schwann cells of the peripheral sympathetic nervous system, including the sympathetic plexus. 